\title{
SAINT JOHN'S WORT NOT SO SAINT
}

Claudia Arnás León ${ }^{1}$, Ana Delia Santana Suárez ${ }^{1}$, Sara Quintana Arroyo ${ }^{1}$, Carmen Acosta *

Calero ${ }^{1}$, Francisco Javier Martínez Martín²

${ }^{1}$ Endocrinology and Nutrition Department, Hospital de Gran Canaria Dr. Negrín, ${ }^{2}$ Endocrinology and Nutrition Department, Clínica San Roque , Las Palmas de Gran Canaria, España

\section{Introduction}

In addition to the medication prescribed by their doctors, patients may recourse to natural medicine and take herbal medications without thinking about their potential side effects and interactions with other drugs.

\section{Case Report}

A 39-year-old female, with personal history of iron deficiency anemia, regular menses but long-standing dysmenorrhea and polymenorrhea and reactive anxiety-depressive disorder, complained of frequent intermenstrual spotting during the last four months. She had also increased emotional lability with several episodes of tremor, chills, sweating, nausea and vomiting. She was initially diagnosed with anxiety crisis.

The patient was taking sertraline and oral contraceptive.

Except for anxious mood and central obesity (BMI $31.2 \mathrm{~kg} / \mathrm{m}^{2}$ ), no pathological signs were found on physical examination.

Lab tests were normal, except for LH $2.04 \mathrm{mUl} / \mathrm{mL}$, FSH $1.45 \mathrm{mUl} / \mathrm{mL}$ and $17-\beta$-estradiol $17 \mathrm{pg} / \mathrm{mL}$.

When the patient was asked about taking any other additional medication, she said that she had been taking a herbal antidepressant for the last four months.

This herbal medication was based on Hypericum perforatum (Saint John's wort), which is a potent inducer of cytochrome P450 and P-glycoprotein. Saint John's wort is implied in many drug interactions, including with antidepressants of the selective serotonin reuptake inhibitor family and oral contraceptives.

Hypericum was withdrawn and, during the follow-up, the patient did not present new episodes of breakthrough bleeding or anxiety crisis.

\section{Conclusions}

Our patient was finally diagnosed with episodic serotonergic syndrome and breakthough bleeding due to interactions between Hypericum and sertraline and oral contraceptive.

An exhaustive medication lookup should be performed in every patient in order to find out if they are taking any herbal medication with potential severe side effects or drug interactions.
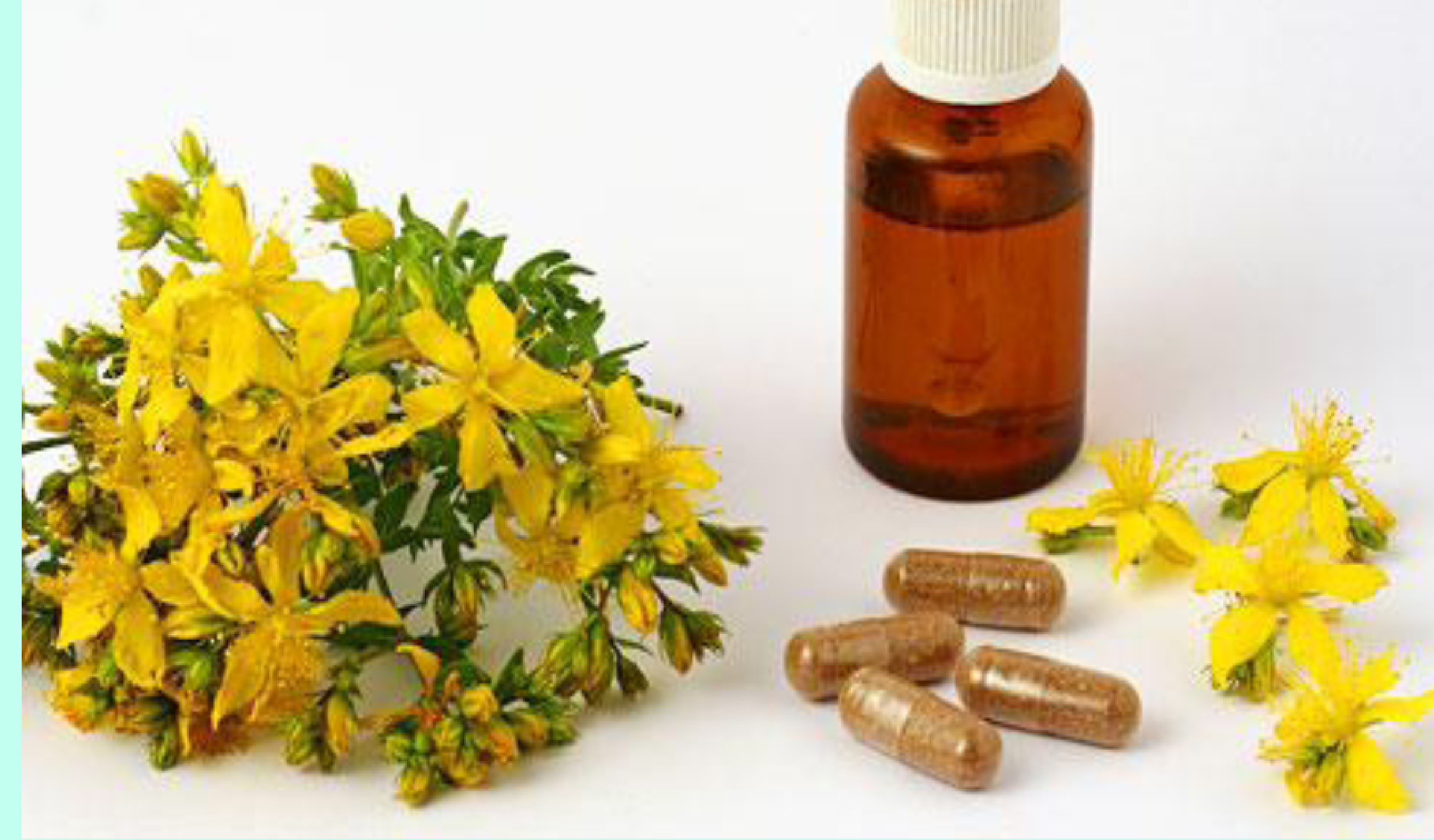